\title{
China, uma breve prospecção: considerações sobre a política de internacionalização brasileira e a pós-graduação em letras
}

China, a brief prospection: considerations on the brazilian internationalization policy and post-graduation in letters

\section{Frederico Augusto Garcia Fernandes}

Universidade Estadual de Londrina - UEL - Londrina - Paraná - Brasil

\begin{abstract}
Resumo: Esse artigo trata sobre potenciais e parcerias acadêmicas entre Brasil e China e faz uma reflexão sobre a política de internacionalização brasileira e de como ela afeta a pós-graduação. Sua metodologia consiste numa viagem de prospecção a universidades chinesas, realizada em 2018, e no diálogo com documentos da Capes, artigos de notícias sobre as ações governamentais e autores voltados para o cenário político e acadêmico brasileiro e chinês. A principal conclusão é de que a China apresenta-se com um enorme potencial para estabelecimento de convênios in e out bound, isso é, para recepção de pesquisadores brasileiros em seu território, como para o envio de estudantes e docentes para atuarem em programas de pós-graduação brasileiros. A área de Linguística e Literatura tem papel fundamental na oferta de cursos de língua portuguesa e capacitação de estrangeiros, bem como nas reflexões sobre interculturalidade.
\end{abstract}

Palavras-chave: china, internacionalização, interculturalidade, pós-graduação, prospecção.

Abstract: This article deals with the potential of partnerships with Brazilian and Chinese academic institutions and discuss the Brazilian internationalization policy, as well as how it affects postgraduate studies. The methodology is based on a 2018 scholar trip to prospect Chinese universities, a consult of Capes documents concerning post-graduation, government decisions latest news, and authors who deals with political and scholar Brazilian and Chinese issues. The article principal conclusion is that China presents a great potential for establishing in- and outbounds cooperation agreements, i.e., for sending Brazilian researchers to Chinese universities, as well as for receiving students and teachers in Brazilian PhD courses. The area of Linguistics and Literature plays an important role by offering Portuguese as second language courses and by fostering interculturality.

Keywords: china, internationalization, interculturality, postgraduate studies, prospection. 


\section{Introdução}

China e Brasil são países de dimensões continentais com diversidade cultural e linguística que não raras vezes acabam por ser determinantes nas relações políticas, econômicas e acadêmicas estabelecidas entre os dois países. A área de Linguística e Literatura acaba por desempenhar um papel muito importante nesse cenário, contribuindo diretamente para uma aproximação social e para uma compreensão humanista entre os dois países.

O artigo propõe uma reflexão sobre como a área pode realizar essa efetiva contribuição. Para tanto, ele se divide em quatro partes. Na primeira, há um enfoque sobre como se dá historicamente a relação entre os dois países, a partir das pesquisas de Bueno (2019), Silva (2018) e Costa (2018), em que é tratada, também, questões de imigração chinesa. A perspectiva histórica assume uma dimensão cultural, à medida em que a construção do olhar de uma cultura sobre a outra passa a ser evidenciada. Dessa forma, as reflexões de Antonio Dimas (2011) e a de Ernesto Araújo (2017) apontam para perspectivas muito diferentes, e é possível dizer, antagônicas, na abordagem culturalista sobre como o Ocidente percebe o Oriente. Tais reflexões alçam uma dimensão política no cenário brasileiro atual, algo que não pode ser ignorado dentro das relações interculturais almejadas pelo meio acadêmico. Essa dimensão se dá com a ascensão de Jair Bolsonaro à presidência pelas eleições de 2018, sendo Ernesto Araújo nomeado seu chanceler.

A segunda parte foca no debate sobre 0 BRICS, um bloco de países emergentes em que o Brasil claramente desempenhou maior protagonismo durante a gestão Lula-Dilma. Para tanto, são vários os estudos sobre o BRICS na área econômica, sendo que aqui foram tratados os de Lenaura Lobato (2018) e Leandro Carvalho (2018). O BRICS também foi fundamental para a aproximação entre China e Brasil, e, por conseguinte, um modelo diferenciado e mais moderno de relação comercial e cultural entre os dois países começou a ser arquitetado. Na terceira parte, foi dado um enfoque sobre as parcerias comerciais, econômicas e acadêmicas. Também nessa parte foram tratados aspectos culturais que se constituem como entraves para as relações comerciais. Aqui, ainda, é dado um panorama sobre práticas de extensão da língua e cultura, bem como de trocas culturais sino-brasileira já evidenciadas, por meio do Instituto Internacional da Língua Portuguesa (IILP), órgão da Comunidade de Países de Língua Portuguesa (CPLP), da Sociedade Internacional Português-Língua Estrangeira (SIPLE) e da Associação Nacional de Pós-Graduação e Pesquisa em Letras e Linguística (Anpoll) e, do lado chinês, o Haban.

A última parte do artigo consta de dados extraídos de uma viagem de prospecção para a província de Fujian, no sul da China, no qual foram visitadas as universidades de Minjiang e Fujian, e na província de Xangai, na qual foi visitada a Shanghai International Studies University. A viagem sintetiza alguns potenciais de parcerias acadêmicas na área de Linguística e Literatura, mas também não deixa de apontar seus entraves.

Pensar a China e compreender a sua relação cultural com o Brasil não se reduz à importância e ao impacto desse país no cenário mundial nos dias de hoje. Por outro prisma, é necessário refletir sobre estratégias de aproximação cultural, no sentido de compreensão de um modus operandi bastante específico nas relações comerciais, as quais se entrelaçam com laços de amizade e de trocas que superam bens de consumo.

\section{Apontamentos sobre Relações Interculturais e Políticas Sino-Brasileiras:}

Os chineses trazem o peso de uma cultura e de uma tradição milenar a qual exerce um verdadeiro fascínio em nós, ao mesmo tempo, em que eles não escondem um ávido estilo de consumo que lembra muito os norte-ocidentais. ${ }^{1}$ A viagem de prospecção,

\footnotetext{
1 O lado consumista chinês não é apenas uma impressão de viagem e pode ser atestado pelos assombrosos números que apontam para o crescimento do PIB por mais de $10 \%$ em 3 décadas, até 2010. O site da BBC apresenta ainda alguns dados que espantam pelos números: os chineses, graças à melhora do poder aquisitivo da população, consomem metade
} 
realizada entre março e abril de 2018, para províncias do sudeste e nordeste da China, possui um sentido de compreender como se operam as relações de trocas culturais, sobretudo, acadêmicas entre Brasil e China, na medida em que objetivou, também, estabelecer contatos e explorar potenciais de parcerias interinstitucionais.

Em outras palavras, a prospecção viabilizou, ad hoc, a busca por interlocutores e por instituições que possibilitaram projetar e expandir novas frentes de conhecimento, por meio da realização de projetos conjuntos. Ela se deu num momento de transformação política, marcado pelo impeachment da presidente Dilma, a ascensão do Governo Temer e disputa eleitoral polarizada entre um discurso social democrata, por um lado, e ultraliberal, por outro, para a presidência no País.

Durante as gestões Lula-Dilma (2003-2016), ao mesmo tempo em que foram realizados inúmeros convênios e acordos de cooperações no campo tecnológico, cultural e, sobretudo, político-econômico, as universidades, de um modo geral, aos poucos despertavam para as relações culturais com os chineses. $^{2} \mathrm{O}$ desafio que se colocava era como lidar com o novo cenário de relações comerciais e políticas, que exigiam, também, uma reflexão cultural.

Segundo o historiador André Bueno (2019, p. 3), a ausência de uma sinologia brasileira é decorrência de o Brasil ter construído um Orientalismo particular, isto é, "atento à erudição, mas preconceituoso na prática social". E, na contramão do que fizeram Cuba e EUA, o Brasil negou durante o século XIX um "espaço de aceitação mais amplo aos asiáticos" (idem). Porém, esse quadro tende a se reverter nas primeiras décadas do século $\mathrm{XXI}$, por

da carne de porco do planeta. A China usou mais cimento entre os anos de 2011 e 2013, do que os EUA durante todo o século $\mathrm{XX}$.

https://www.bbc.com/portuguese/noticias/2015/09/150926 chin a urbanizacao cc - Acessado em 23/05/2019.

${ }^{2}$ O site do Itamaraty traz uma sinopse desde 1974, quando o País reestabelece relações diplomáticas com a China. É visível como nos anos de administração PT (2003-2016), nos governos Lula e Dilma, esses acordos foram intensificados por ações como a criação da Comissão Sino-Brasileira de Alto Nível de Concertação e Cooperação (COSBAN), em 2004, e pela prática política e estreitamento econômico mediado pelo bloco BRICS. A respeito, ver: http://www.itamaraty.gov.br/pt-BR/fichapais/4926-republica-popular-da-china - Acessado em 23/05/2019. meio de um fenômeno social: a nova onda de imigração em massa de chineses para o Brasil, que tende a ter impactos significativos também no cotidiano de médias e grandes cidades. Transformações significativas na paisagem urbana de cidades como, por exemplo, São Paulo (SP) e São Gonçalo (RJ), por conta da imigração chinesa, já estão sendo observadas e estudadas na academia, conforme indicam as pesquisas de Silva (2018) e Costa (2018).

Mas essa presença chinesa no Brasil, atestada também pela instalação de empresas em cidades de porte médio, como é o caso de Londrina, conviverá com uma adversidade ideológica que não é recente. O retrato de uma revolução execrada, que mais esconde o pavor e a ignorância comumente proliferada no Brasil sobre o comunismo, e a circulação de um produto popular de má qualidade, denominado popularmente "xing ling", são alguns exemplos que atestam uma incompreensão brasileira sobre a cultura chinesa, esvaziando-a de sua real densidade. Por isso, tratar de uma questão chinesa pode ser motivo de grande embaraço, já que os equívocos culturais se decantam inclusive no uso vernacular, fazendo com que preconceitos se integrem a práticas culturais percebidas na vida diária. Foi Antonio Dimas quem observou:

Da pesquisa rápida pelos dicionários de nossa língua, nos clássicos ou nos escolares, anotase que a palavra chinesice carrega divergências ligeiras, mas convergentes. Grosso modo, a palavra define "objeto de pequeno porte, de elaboração intricada, feita com paciência e minúcia, mas de utilidade incerta". Em francês, chinoiserie comporta também a ideia de "complicação extravagante". Chinese puzzle, em inglês, significa coisa complicada, difícil de ser resolvida. No espanhol, entre as várias acepções, chino comporta ainda a de "trabalho extremamente laborioso, geralmente por sua minúcia”. (DIMAS, 2011, p. 79).

$\mathrm{Na}$ virada do século XIX para o XX, a adversidade a práticas culturais chinesas enraíza-se no argumento eurocêntrico da fundação da nação brasileira, que percebe na diferença asiática uma ameaça ao seu espírito de nacionalidade (BUENO 2019, p. 4). Essa adversidade se faz presente nos 
dias atuais por meio de um conflito político bipolar, operado por uma lógica semelhante à da Guerra Fria, o qual vem ganhando expressão político-institucional com a ascensão da extrema direita à presidência no Brasil.

Os mecanismos de promoção dessa adversidade originam-se no ressurgimento, em escala global, da prerrogativa de ameaça do Oriente ao Ocidente, por meio do desaparecimento da fé, cultura e tradição ocidentais. Trata-se de uma ideologia que ganha força com a posse de Donald Trump na presidência dos EUA, pelas eleições de 2016, mas tem sido notada pela ascensão ao poder de governos xenófobos ou pelo crescimento de blocos conservadores em parlamentos de países, como Polônia, Áustria, Hungria, Noruega, Dinamarca, Suíça e Itália. A própria Comunidade Europeia convive, desde 2009, com um bloco de opositores, afinados com ideias conservadores e nacionalistas, intitulado Aliança dos Movimentos Nacionais Europeus, que congrega partidos de, ao menos, 25 nacionalidades. No cenário político atual, acentuam-se posicionamentos anti-imigração, inspirados por uma revalorização da identidade euro-ocidental e pela intolerância a valores maghreb, em que direitos humanos, não raramente, são violados nos campos de refugiados espalhados pela Comunidade Europeia.

Essa lufada nacional-populista atingiu também - Brasil com protestos, operações do judiciário e movimentos populares que acabaram por ter como resultado 0 impeachment da presidente Dilma Roussef, em 2016, e a eleição de Jair Bolsonaro nas eleições de 2018. O Brasil, no primeiro semestre de 2019, tem dado sinais claros de uma política externa alinhada com os países governados por líderes de ideologia nacional-populista, principalmente os EUA, ao declarar que atuará para "neutralizar" a importância da China entre os países BRICS e anunciar que transferiria a embaixada brasileira para Jerusalém, contrariando a comunidade árabe. Assim, a política internacional brasileira tem tido ações que revelam um posicionamento antiorientalista.

Em 2017, Ernesto Henrique Fraga Araújo, que viria a ser nomeado chanceler da administração Jair Bolsonaro, publicou, na revista Cadernos de Política Exterior, do Instituto de Pesquisa de Relações Internacionais, o artigo "Trump e o Ocidente", em que compara a posse de Donald Trump na presidência dos EUA a um passe de ouro do futebol americano (Hail Mary pass). Uma presença, segundo ele, capaz de livrar o Ocidente do colapso cultural provocado pelo Oriente. O artigo eivado de apelo à fé como essência da construção de uma nação, com ataques direto ao relativismo cultural, considerado pelo autor como "absolutismo antiocidental" (ARAÚJO, 2017, p. 348), soa como apologia à intolerância, opondo-se frontalmente ao conceito de diversidade. ${ }^{3}$ Esse posicionamento político em relação ao Oriente coloca-se como um radical apelo ao nacionalismo de base cristã, na defesa de uma história Ocidental, eurocêntrica, que tem como desdobramento tornar a política refratária a condições culturais e econômicas num mundo de nações conectadas.

Fica claro que os interesses por detrás dos ataques à cultura e ao culturalismo deixam transparecer um apelo econômico, tendo como epicentro a guerra comercial entre os Estados Unidos e China. Como Donald Trump investe contra o "globalismo", franqueando, com isso, um protecionismo econômico para os EUA, principalmente na disputa comercial com a China, Araújo e a política internacional bolsonarista ignoram a importância de mercado que os orientais, sobretudo árabes e chineses, mantêm com o Brasil na atualidade. Além disso, não é demais lembrar que, dos cinco países BRICS, três encontram-se na Ásia e são parceiros comerciais importantes.

A erudição apresentada pelo autor de "Trump e o Ocidente", demonstrada pelo emprego de filósofos como Nietzsche e Heidegger, de escritores como Ésquilo, Virgílio e Pessoa, pela leitura de textos em alemão, inglês, francês e italiano, esvanece diante de sua dificuldade e resistência em tratar e debater conceitos caros ao culturalismo, como "diferença",

\footnotetext{
3 São várias as passagens em que a intolerância se coloca como um efeito nacionalista, na perspectiva de Araújo. Pinço uma delas: "[...] o Ocidente não nasce no diálogo nem na tolerância, nasce na defesa de sua própria identidade." (ARAÚJO, 2017, p. 336).
} 
"diversidade" e "cultura", os quais, para ele, são responsáveis por

[...] enfraquecer o ser humano, torná⿴囗十 lo uma paçoca maleável incapaz de resistir ao poder do estado, criar pessoas inseguras, desconectadas, incapazes de assumir um papel social próprio ou de ter ideias que não sejam os chavões politicamente corretos veiculados na mídia. (Idem, p. 339).

Ao rejeitar o debate cultural, Araújo distanciase, assim, da história brasileira, da sua particularidade (des)ocidentalizada, incorporada pela presença indígena e negra da formação nacional. É nessa negação, cujo objetivo parece ser 0 de disfarçar o caráter nacional brasileiro de uma "pureza" identitária - a qual nunca operou, de fato, na história fundadora da nação -, que o chanceler encouraça a intimidade da cultura brasileira, deixando flagrar um campo de representação subjetiva das experiências ocidentais sobre os orientais. Esse campo, desde anos 70, tem sido apresentado e debatido por Edward Said, quem cunhou a expressão "orientalismo". Para ele, "o orientalismo é - e não apenas representa uma considerável dimensão da moderna cultura político-intelectual e como tal tem menos a ver com o Oriente que com o 'nosso' mundo" (SAID, 1990, p.24).

A guinada política brasileira das últimas eleições tem provocado incertezas no campo econômico e cultural. A administração Bolsonaro tem sido marcada pela interdição do debate cultural em órgãos importantes como o Ministério da Educação, Ministério da Cidadania, ao colocar intelectuais numa posição de defesa dos princípios humanitários e, também, de teses das Ciências Humanas. ${ }^{4}$ Uma política alavancada ainda pelo encolhimento da participação de agências governamentais - como

\footnotetext{
${ }^{4}$ Tai ataques ocorrem de forma generalizada. No dia 26 de abril de 2019, o presidente Jair Bolsonaro, via Twitter, defendeu o corte de verbas aos cursos de Filosofia e Sociologia, alegando má empregabilidade do dinheiro do contribuinte. Em 15 de maio, o Ministro da Educação, Abraham Weintraub, na Câmara dos Deputados, afirmou que as "As ciências sociais aplicadas, humanidades e linguística geram pouquíssimas publicações com impacto científico", acrescentando que a concentração de bolsas está justamente nessas áreas que "não produzem ciência" (in: MARÉS, 2019).
}

CAPES e CNPq - no financiamento da pesquisa ${ }^{5}$ e pela extinção do Ministério da Cultura. Ações que, de modo direto ou indireto, acabam por paliar iniciativas de cooperação internacional, sobretudo, com países do lado Oriental.

Tais incertezas intensificam-se pela falta de clareza em relação à estratégia brasileira na política BRICS e, consequentemente, à duração e/ou renovação das parcerias Brasil-China existentes. Evandro Menezes de Carvalho, coordenador do núcleo de estudos na FGV sobre os dois países, manifestava suas dúvidas sobre como Bolsonaro reagiria à próxima cúpula dos presidentes no BRICS, realizada em novembro de 2019 em Brasília. Jair Bolsonaro, desde a posse, declarou abertamente um alinhamento ideológico com os EUA, resultando, segundo Carvalho (2018, p. 35), numa "subalternidade incontida" do governo brasileiro àquele país. Ainda tomando como base a linha argumentativa de Evandro Menezes de Carvalho (2018), a oferta de uma base militar aos EUA e a retirada do Acordo de Paris sobre Mudanças Climáticas sem uma justificativa que atenda aos interesses nacionais refletem uma imprudente $e$ desastrosa guinada do Brasil em suas relações diplomáticas. Tanto é que, sob pressão de setores da sociedade que apoiavam o governo, o presidente recuou em algumas delas como o caso da transferência da embaixada brasileira para Jerusalém. ${ }^{6}$

A recuperação do protagonismo brasileiro no bloco BRICS passa por ações de aproximação cultural com os países envolvidos, entre as quais o estímulo ao intercâmbio acadêmico. A

\footnotetext{
${ }^{5}$ Trata-se do congelamento de $42 \%$ das verbas do Ministério da Ciência e Tecnologia e Inovação anunciado em março pelo governo federal e do corte de $25 \%$ das verbas do Ministério da Educação. (NATURE, 2019).

6 Até mesmo na transcrição do discurso de Jair Bolsonaro na 11 a Sessão Plenária da Cúpula do BRICS, o presidente chega a verbalizar a importância da parceria econômica do BRICS, prospecta parcerias na área agrária, tecnológica, de engenharias e de saúde, mas ignora a importância das humanas nesse processo de construção de uma internacionalização mais sólida. O discurso na íntegra pode ser lido no site do Itamaraty: http://brics2019.itamaraty.gov.br/espaco-multimidia/noticias/116transcricao-do-discurso-do-presidente-da-republica-jairbolsonaro-na-sessao-plenaria-da-11-cupula-do-brics - Acesso 28 nov. 2019.
} 
internacionalização das universidades, por meio de convênios in e out bound, coloca-se como uma necessidade premente para o desenvolvimento da ciência. Ciência aqui deve ser pensada não apenas a partir da produção de bens nas áreas de tecnologia, engenharia, agrária, mas também como base em temas emergentes que blocos como o BRICS enfrentam, tais como: intolerância, violência, desigualdade, pobreza, bem como novas formas de produção e circulação de conhecimento. Tais temas são decorrentes de trocas culturais que se constituem fenômeno e objeto de estudo caros às Ciências Humanas e, também, à área de Linguística e Literatura. Nesse ponto se constitui um debate de suma importância para o BRICS: estratégias de melhoria da qualidade de vida de suas populações, mediada pela interculturalidade.

\section{BRICS e Interculturidade}

As relações internacionais entre o Brasil e a China passam pela arquitetura de um grande bloco de países denominado BRICS, cuja importância tanto em nível cultural como econômico não deve ser ignorada. A área de Linguística e Literatura tem sido provocada a pensar a competência intercultural, franqueada pela junção de países com histórias, línguas e tradições muito diferenciadas.

O termo BRIC, como é sabido, surgiu no ano de 2001, quando o então CEO do Goldman Sachs, Jim O'Neil, cunhou essa sigla em seu artigo "Building Better Global Economy". Nesse artigo, o autor elencava, entre os G20, 4 países industrializados os quais teriam condições de se destacar como potência econômica: Brasil, Rússia, Índia e China. A primeira reunião se deu no ano de 2009 , sendo que, no ano seguinte, a África do Sul se juntou ao grupo alterando a sigla para BRICS. Desde então, a pauta dos encontros anuais tem se desdobrado em direção a relações políticas do grupo no cenário internacional. O BRICS é um dos grupos econômicos mundiais mais importantes na atualidade. Os 5 países têm um grande tamanho agregado de $29,6 \%$ do território planetário; $28 \%$ do PIB global e $41,2 \%$ da população mundial; alto potencial de crescimento, principalmente devido à atual má distribuição de recursos, e ao estoque relativamente baixo de capital humano (LOBATO, 2018). Um grupo constituído por interesses comuns, como os países BRICS, não pode desprezar os potenciais de trocas científicoacadêmicas e de políticas culturais advindos de acordos econômicos estabelecidos.

Juntos, os BRICS estão entre as 10 línguas mais faladas no mundo, considerando o coeficiente populacional: $1^{\circ}$ Chinês, $3^{\circ}$ Inglês, 4ำ Português, 6ำ Hindi e 8을 Russo (OMONDI, 2019). Eles estão à frente do alemão, francês e italiano. Os BRICS têm diferentes linguagens cujo pensamento produz várias maneiras de apresentar informações e fazer negócios. Relações comerciais produtivas dependem de trocas linguísticas e da análise comunicacional, de bases interculturais. O tripé cultura, política e negócios retroalimenta-se. O desenvolvimento econômico almejado com protocolos de trocas tecnológicas precisa levar em conta relações interpessoais, normas de comportamento, crenças e valores que permeiam os agentes envolvidos nessas trocas. E isso justifica a participação ativa da área de Linguística e Literatura, no sentido de promover a integração cultural entre os países BRICS.

\section{China: um à parte}

Em 2018, graças a uma intricada rede acadêmica que envolvia contatos no Canadá e na China, e à visita de uma amiga sino-canadense ao Brasil, acabei recebendo o convite para ser professor visitante na jovem Universidade de Minjiang, localizada na província de Fujian, mais especificamente na sua milenar capital Fuzhou.

O convite, em princípio, era para um ano sabático, com o propósito de ministrar cursos de Língua Portuguesa e Cultura Brasileira e desenvolver um projeto de pesquisa sobre a temática de trocas culturais entre o Brasil e a China, dentro das relações do BRICS. Porém, por questões internas à instituição de origem a qual estou vinculado como docente, a liberação acabou sendo concedida por apenas 40 dias, por isso a proposição inicial foi reajustada para 
uma viagem de prospecção.

40 dias podem parecer pouco tempo para uma imersão na cultura chinesa, mas a estada em território chinês possibilitou encontrar e interagir com pessoas que foram capazes de se comunicar nas línguas que também sou fluente e que, gentilmente, traduziram o "movimento de mundo" até então incompreendido por mim. O foco da viagem de prospecção foi o de estabelecer vínculos com universidades chinesas que estariam dispostas a fechar acordos com a Universidade Estadual de Londrina, sobretudo, na área de Letras e Linguística.

Uma viagem relativamente rápida, considerando seu propósito, com visita a universidades em regiões diferentes, museus, centros de pesquisa, deve seu êxito em grande parte à receptividade das pessoas. Não cabem à China, considerando sua população e sua enorme extensão territorial, generalizações de identidade. A complexidade de seu caráter nacional aloca-se numa longeva história, em que se enraízam diferentes etnias, línguas, hábitos e costumes. A impressão trazida dos chineses dessa viagem está longe de traduzir esse caráter e reflete muito mais a experiência de um trânsito por culturas do que um pretenso quadro estático de uma identidade nacional.

A China é um país bastante extenso e com grande diversidade cultural, nesse aspecto semelhante ao Brasil, porém com uma superpopulação estimada em 1.379 bilhões de pessoas. Trata-se de um país de cultura milenar que passou por várias revoluções sociais, sendo atualmente de economia aberta, mas de um regime não democrático. Por sucessivos anos, a China tem desempenhado a melhor performance econômica junto aos BRICS, com crescimento do PIB que chegou a superar os $12 \%$ a.a e apresentou um crescimento de 6,6\% para 2018, enquanto 0 crescimento brasileiro foi de apenas $1,1 \%{ }^{7}$

\footnotetext{
${ }^{7}$ A respeito, ver as reportagens do Portal G1: "PIB do Brasil cresce $1,1 \%$ em 2018 e ainda está no patamar de 2012", de $28 / 02 / 2019$

https://g1.globo.com/economia/noticia/2019/02/28/pib-do-brasilcresce-11-em-2018.ghtml e "Economia da China cresce 6,6\% em 2018; taxa é a menor desde 1990", de 21/01/2019. In: https://g1.globo.com/economia/noticia/2019/01/21/economia-dachina-cresce-66-em-2018.ghtml - Acessado em 28/05/2019.
}

O equilíbrio social chinês é sensível quando se transita pela paisagem urbana, as cidades surpreendem pela ostentação de edifícios modernos, com linhas de metrô, aeroportos, estações de trem que permitem o deslocamento rápido e seguro pelo país. Para além da impressão provocada pelas edificações e arquitetura moderna, há os dados de combate à pobreza que ainda parecem não atingir uma eficaz política de distribuição de renda, mas que garantem o acesso de bens de consumo por grande parte da população. Dados do China National Human Development Report 2016 revelam um acentuado crescimento econômico desde 1978, ao passo que projeta a China para a maior economia mundial em 2030 (2016, p. 24).

$\mathrm{Na}$ China, apesar de os índices de desigualdade, levando-se em conta o indicador GINI, ainda serem altos e exigirem uma melhor atenção do governo no combate a eles, é visível a redução da pobreza desde a abertura do governo Xiaoping, em 1978. As ações de combate à pobreza, nos dias atuais, refletem-se na valorização da educação como forma de ascensão social, na sensação de segurança ao caminhar pelas ruas e, de modo geral, na qualidade de vida das pessoas.

Nesse boom econômico chinês, que perdura por mais de duas décadas, muitos colleges tornaramse universidades ${ }^{8}$. O investimento do país no ensino superior tem como efeito direto a melhoria progressiva da qualidade da educação, dos avanços científicos e das estratégias de internacionalização atestadas pelas posições em rankings internacionais das universidades chinesas. De acordo com Gong \& Martinez (2018), o ensino superior chinês teve seu primeiro estágio de crescimento nos anos de 1950, marcado pela ascensão do Partido Comunista ao poder, em que centenas de universidades e colleges foram criados atendendo a demanda de províncias e pequenas cidades. Ainda segundo às autoras, em 1978, com a abertura econômica de Deng Xiaoping, o ensino entra numa fase de atendimento à elite,

\footnotetext{
8 Muitas universidades ainda não completaram 20 anos de existência e têm almejado um crescimento acadêmico por meio de cooperações no exterior, como é o caso da Minjiang University.
} 
reinstituindo o exame nacional para acesso. Nos anos 90 , o ensino superior atinge uma nova fase com o projeto de massificação, no qual teve como resultado a inserção de mais de $23 \%$ de jovens com idade entre 18 e 22 no ensino superior. O aumento de jovens no ensino superior correspondeu também ao aumento de Instituições de Ensino Superior (IES) privadas na China. Lá como no Brasil, as IES públicas apresentam os melhores ranqueamentos. Entre os BRICS, segundo dados do QS World University Rankings 2019, por exemplo, a China possui 10 instituições ranqueadas entre as 100 melhores do mundo, enquanto, no contexto BRICS, a Rússia possui apenas 1 e Brasil, Índia e África do Sul nenhuma. ${ }^{9}$

A China, apesar da política brasileira internacional atual, ainda é uma das principais parceiras econômicas do Brasil. Desde 1974, quando foram retomados tratados de cooperação internacional com este país, as transações saltaram de cerca de 7 bilhões de dólares em 2003 para 66,6 bilhões em 2018, atingindo um superávit de 23,3 bilhões nesse mesmo ano (CARVALHO, 2018, p. 38). Além disso, destacam-se as parcerias em projetos estratégicos como lançamento de satélites de monitoramento do clima para agricultura, propostas de melhoria de infraestrutura para escoamentos de commodities, entre outros.

Numa perspectiva cultural, no entanto, colocam-se algumas barreiras que dificultam 0 avanço das relações comerciais entre os países, dentre as quais cabe destacar:

a) Incompreensão de Procedimentos e Protocolos nas Formas de Negociação: nossos empresários passam a negociar com normas de protocolo bastante distintos do modelo Ocidental, sem se dar conta do impacto que o Confucionismo e o Taoismo têm na forma de negociar chinês.

b) Necessidade de Ampliação de Networking: a cultura chinesa tradicionalmente é formalizada pelas relações e contatos pessoais em detrimento da formalização contratual ou legislativa, ou seja,

\footnotetext{
9 In: https://www.topuniversities.com/university-rankings/worlduniversity-rankings/2019 - acessado em 28/05/2019.
}

relações e contatos pessoais são fundamentais para o desenvolvimento de parceria. O guanxi, originado da filosofia confucionista, descreve os modelos de relações pessoais para o trabalho, podendo ser resumido no seguinte enunciado: primeiro conhecer, depois ver se é possível ser amigo para, por fim, abrir para uma possibilidade de negócio. (GAO et all., 2012)

O fato de o Brasil ser um BRICS fortalece o argumento para a construção de acordos e parcerias com universidades chinesas. Esses acordos acabam sendo vitais para promover uma política de internacionalização entre programas de pósgraduação. O documento de avalição do Plano Nacional de Pós-Graduação 2018 (PNPG) da CAPES aponta para a internacionalização como um tema convergente, ou seja, entende a internacionalização como uma ação que deve ser efetiva na promoção da pesquisa e da formação do pesquisador desenvolvida durante sua passagem pela pós-graduação stricto sensu. Mas reconhece que: "A internacionalização, na área de pós-graduação, ainda é fomentada por programas governamentais descontínuos e que mudam de foco constantemente." (CAPES, 2018, p.13).

A própria agência disponibiliza editais de financiamento para a cooperação internacional na pós-graduação: a Escola de Altos Estudos (EAE), responsável por financiar a vinda de professores do exterior para ministrar cursos e/ou desenvolver atividades de pesquisa junto à pós-graduação; o Programa Institucional de Internacionalização (CAPES-PrInt), com o objetivo principal de formação de redes de pesquisas internacionais, de modo a aprimorar a produção acadêmica nacional; e o Cooperação Estratégica com o Sul Global (COOPBRASS), que financia missões de estudo no exterior e tem por objetivo estabelecer parcerias institucionais com IES de países que o Brasil possui tratado de cooperação em educação, entre eles, a China. Enquanto o primeiro custeia a vinda do pesquisador estrangeiro ao País, o segundo e o terceiro viabilizam tanto a vinda como também a saída de pesquisadores brasileiros para estágios de 
pós-doutorado no exterior. Há, no entanto, uma aparente assimetria entre os três programas de financiamento já que no EAE e COOPBRASS é facultada a aplicação de pesquisadores vinculados à pós-graduação, enquanto no CAPES-Prlnt podem concorrer aos editais somente IES.

O paradigma de internacionalização da CAPES assenta-se no fluxo in e out bound de discentes e pesquisadores, sendo que os atuais editais reservam essa possibilidade. O problema principal continua sendo a descontinuidade da oferta de editais por estes programas de financiamento, em que, por exemplo, por conta do contingenciamento de verbas na educação brasileira, não há previsão de novos editais da EAE. Existem outras formas de envio de pesquisadores como o Doutorado Pleno no Exterior, o Programa de Doutorado-sanduíche no Exterior, e o Pós-Doutorado no Exterior, mas trata-se de programas de financiamento que atingem fases específicas da formação do pesquisador. Até mesmo o Pós-Doutorado no Exterior exige que o candidato tenha menos de 8 anos de formação como doutor.

Examinando a questão mais de perto, a área de Linguística e Literatura possui, seja pelo papel exercido nos núcleos de ensino de língua estrangeira ou pelo culturalismo literário, ou ainda, pelo ensino de português para estrangeiros, uma vocação clara para a internacionalização. Esse trunfo pode ser melhor aproveitado caso associações, como a Associação Nacional de Pós-graduação e Pesquisa em Letras e Linguística (ANPOLL), promovam diretrizes para a disseminação da língua portuguesa e da literatura brasileira no exterior, levando em conta o know-how das pesquisas desenvolvidas junto a seus programas. Algumas ações da ANPOLL junto à CAPES foram feitas no ano de 2018, mas foram interrompidas com a mudança de governo e, consequentemente, do quadro de diretores e da presidência da agência, além é claro da mudança do eixo nas relações internacionais, conforme demonstrado acima. ${ }^{10}$

\footnotetext{
${ }^{10}$ A atual diretoria da ANPOLL, eleita para o biênio 2018-2020, reuniu-se com a presidência, a Diretoria de Relações Internacionais e Diretoria de Programas e Bolsas no País, em outubro de 2018, para tratar de iniciativas de aproximação e de convênios com universidades chinesas, bem como sobre a
}

Outro projeto na área que merece destaque é o do Instituto Internacional da Língua Portuguesa (IILP), o órgão da Comunidade de Países de Língua Portuguesa (CPLP) mandatado para a promoção e a divulgação do português. O ILLP já opera com o Portal do Professor de Português Língua Estrangeira / Língua Não Materna (PPPLE), disponibilizando unidades didáticas para o ensino de português a chineses. As unidades foram produzidas em Macau e contam com parceria da Sociedade Internacional Português-Língua Estrangeira (SIPLE). Tais iniciativas, tanto da ANPOLL como da SIPLE consistem em agregar a parceria cultural focada no ensino da língua e na circulação de produções artísticas, sem perder de vista relações políticas e comerciais. Com isso, a proposta de internacionalização não se esgota em si, pois gera benefícios econômicos e sociais que visam a melhorar a condição de vida das sociedades envolvidas.

A pós-graduação, ao incorporar um modelo como o exposto, estimula uma nova compreensão da realidade, propiciando também o diálogo entre diferentes disciplinas do conhecimento. Nesse sentido, as áreas de Humanas e Letras envolvidas em projetos com esse caráter, estariam promovendo a inovação social. A CAPES é a agência que tem a prerrogativa de propor editais para franquear acordos bilaterais específicos entre IES chinesas e brasileiras, oportunizando 0 fluxo de mão-dupla entre pesquisadores e discentes dos dois países e, também, gerando editais específicos para a promoção da inovação social.

Uma outra face a ser focada dentro dessas relações poliédricas sobre as práticas interculturais Brasil-China diz respeito ao ensino da língua portuguesa em território chinês. O professor da Universidade de Coimbra, Carlos André, que concomitantemente foi professor do Instituto Politécnico de Macau entre 2013-2018, relata que o ensino de português na China foi retomado na década de 1970, sendo o início do século XXI o

necessidade de inclusão da área na chamada Universidade em Rede dos BRICS. 
momento de sua grande explosão. Segundo André (2017, p. 199), em 10 anos, o número de IES onde se leciona a Língua Portuguesa aumentou de 6 para 37, estimando a atuação de mais de 200 docentes e cerca de 2 mil estudantes. A Universidade de Coimbra e o Instituo Camões em Portugal têm protagonizado um importante papel nessas parcerias para formação docente e discente de recursos humanos aptos para atuar com o ensino da Língua Portuguesa e suas literaturas.

Já existe uma demanda pela integração cultural entre Brasil e China, devido à instalação de empresas de capital chinês no Brasil, o que tem impulsionado a demanda por cursos de mandarim e a capacitação do empresário brasileiro aos modelos de negociação chinesa, como o guanxi. Em nosso País operam 10 institutos Confúcio em universidades públicas e particulares, cobrindo as 5 regiões. Tais institutos não atendem à demanda nacional pelo acesso à língua e cultura chinesa, mas desempenham um importante papel na conexão cultural entre os dois países. Além disso, o Hanban, órgão governamental chinês responsável pela instalação e gerenciamento dos institutos Confúcio, vem demonstrando sinais claros de restrição à abertura de novas unidades em países que já possuem mais de um instituto, como é o caso brasileiro.

As ações no âmbito institucional podem ser melhor otimizadas com relatos de viagem de prospecção como abaixo apresentados. O objetivo não é de apresentar instituições de uma região pouco explorada em termos de desenvolvimento do Português, como é o caso de Fujian, como de sinalizar para parcerias em andamento e seu potencial para propostas de projetos acadêmicos interdisciplinares no futuro, envolvendo a pósgraduação.

\section{Viagem de Prospecção em Fujian e Xangai}

A viagem ocorrida entre os dias 1 de março a 10 abril teve por objetivo a oferta de cursos e palestras em universidades chinesas, além de realizar, para a Assessoria de Relações Internacionais e a Pró-Reitoria de Pesquisa e PósGraduação da UEL, uma prospecção sobre a possibilidade de convênios internacionais. Os relatos abaixo compreendem dados de 3 universidades cujas realidades e regiões são bastante distintas. O objetivo é trazer um dado de realidade acadêmica, no qual são evidenciadas algumas fragilidades, sobretudo no tocante à língua, impeditivas do estreitamento entre pesquisadores dos dois países.

\subsection{Minjiang University}

A Minjiang University é uma universidade pública relativamente nova na província de Fujian, sul da China, tendo sua criação sido aprovada em 2002. Porém, sua origem remonta aos de 1950, com o Fuzhou Teacher's College. A instituição tem ao longo de sua trajetória agregado vários intelectuais e líderes importantes, como, por exemplo, o atual presidente da China, Xi Jinping, que foi o presidente do College nos anos 90. Dada a importância estratégica para a região, Minjiang University apresenta um quadro bastante rápido de crescimento e evolução, o que já a coloca como a segunda universidade mais importante regionalmente. Tem uma comunidade acadêmica de mais de cerca de 19 mil alunos, em período integral, 1.100 docentes com dedicação exclusiva. Oferece 55 cursos de graduação, mas conta ainda com uma pósgraduação bastante incipiente com apenas um mestrado e 28 cursos de especialização e de aprimoramento profissional.

Em reunião com o reitor, prof. Dr. Zonghua Wang, foi enfatizado o interesse por intercâmbios entre pesquisadores e discentes e a capacitação docente em programas de pós-graduação brasileiros, já que seu quadro é constituído por $25 \%$ de professores com o título de doutor. Essa conversa inicial resultou numa reunião com professores e próreitores para apresentação de programas stricto sensu com conceito 4, 5, 6 e 7 da UEL. Durante a reunião, foram pontuadas algumas dificuldades pelos professores chineses que certamente contribuirão para a elaboração de metas a serem pensadas pelos 
convênios interinstitucionais. Entre elas, cabe destacar:

a) Ausência de oferta de cursos em língua inglesa na pós-graduação brasileira, o que faz com que os pesquisadores deem preferência para universidades europeias e norte-americanas.

b) Dificuldade de acesso à informação em língua inglesa em boa parte dos sites de programas de pós-graduação no Brasil.

A língua ainda é uma grande barreira para a captação de alunos e professores/pesquisadores estrangeiros para o Brasil. O aprendizado da língua portuguesa em um bom nível de proficiência para falantes do chinês levaria pelo menos um ano e meio de estudo, a oferta de português na China concentrase em Macau e em grandes cidades como Pequim e Xangai, ambas com mais de 20 milhões de habitantes. Na cidade de Fuzhou, não há oferta sistemática de cursos de língua portuguesa nas 3 universidades visitadas.

A Minjiang University conta com uma excelente infraestrutura. Possui 4 campi na cidade, numa área total de $1.618 .400 \mathrm{~m}^{2}$. A biblioteca central encontra-se alocada em dois edifícios de 4 andares cada e possui um acervo de mais de 3 milhões de títulos. Há 15 laboratórios em todas as áreas e 6 incubadoras de projetos - think tank. As salas de aulas são amplas e arejadas, todas climatizadas e com equipamento multimídia. A cidade universitária conta ainda com várias cantinas e lojas, hotel para hospedar visitantes e dormitórios para os estudantes e professores.

Alunos do Bacharelado em Língua Inglesa foram os beneficiados diretos da visita, devido à proximidade temática e ao fato de que o curso e as palestras foram ministrados em inglês. $\mathrm{O}$ bacharelado se divide em duas modalidades: língua inglesa voltada para negócios e administração e língua inglesa e tradução. O curso encontra-se localizado na Escola de Humanidades e Comunicação, a qual oferta: Chinês Língua e Literatura, Educação Internacional em Língua Chinesa, Propaganda, História, Herança Cultural e Museologia, Inglês e Japonês. A universidade possui grande expertise na formação de professores de chinês e, por tal motivo, tem liderado a parceria com o Instituto Confúcio no Canadá, junto à Brock University, na província de Ontário. Além disso, a instituição tem desenvolvido acordos de cooperação internacional com universidades nos Estados Unidos, Austrália, Canadá e Suíça. Como resultado desses acordos, a universidade é sede também do Melbourne Institute of Techonology.

\subsection{Shanghai International Studies University}

A Shangai International Studies Unviersity é uma instituição pública com dois campi na cidade de Xangai. A visita focou na School of European and Latin American Studies (SELAS). Este centro universitário possui 5 cursos de graduação nas seguintes línguas: Português, Espanhol, Italiano, Grego, Alemão, com 4 programas de mestrado e um de doutorado. Trata-se de uma universidade voltada especificamente para políticas de internacionalização, demonstrando larga experiência em acordos e convênios, atestada pelas mais de duas dezenas de universidades conveniadas da Europa e Américas. A universidade conta com uma sólida infraestrutura, sendo que os estudantes cursam em tempo integral. Encontra-se classificada entre as 147 melhores universidades dos países BRICS, e as 50 melhores da China, de acordo com o QS World University Rankings 2019.

As ações nesta IES focaram em estabelecer parcerias acadêmicas em pesquisa e também na possibilidade de ser firmado acordos na área de Língua Portuguesa e cultura brasileira.

Destacam-se alguns profissionais com atuação no mestrado em Língua Portuguesa, voltados para o Brasil: o professor Gonçalo Zhang Weiqi (Vice-diretor do Departamento de Português, Diretor do Centro Brasileiro de Estudos e Vice-secretário Geral do Centro de Estudos Parlamentares) e a professora Catarina $\mathrm{Xu}$ (Diretora do Departamento de Português). A universidade já possuía um acordo na área de língua portuguesa com a Universidade de São Paulo em nível graduação, numa ação bilateral de recebimento de estudantes e foi firmado com a 
UEL um acordo geral, para ser feitas parcerias na pós-graduação na área de Linguística e Literatura.

O curso de Literatura e Língua Portuguesa foi criado em 1977 e oferta 21 vagas anualmente para estudantes interessados em fazer graduação em língua portuguesa. Possui um mestrado com cerca de 4 alunos pesquisando temas sobre o Brasil. Foi observada uma demanda crescente pela pósgraduação em língua portuguesa e, assim, o estabelecimento de parcerias para a realização de cursos na modalidade sanduíche para a pósgraduação.

Essa instituição conta com apoio de pesquisa do Centro de Estudos Brasileiros, dirigido pelo professor Gonçalo Zhang Weiqi. O Centro tem por finalidade divulgar a cultura brasileira e demonstra potencial para atuar como parceiro na realização de eventos e de publicações.

\subsection{Fujian University}

Localizada na província de Fujian, a Fujian Business University é uma universidade pública com foco em comércio internacional, administração e contabilidade. Conta com 3 campi, localizados nas cidades de Lianjian, Mawei e Gulou. Possui mais de 15 mil estudantes e 600 docentes com dedicação exclusiva. A instituição teve seu reconhecimento recente, mas como a Minjiang University, sua origem está atrelada à educação secundária e técnica. 0 perfil define-se com a criação, no ano de 1906, da Escola de Negócios de Fujan. A universidade encontra-se estruturada em 11 escolas e departamentos. Oferta 10 cursos de graduação e 40 especializações.

Em reunião com seu reitor, prof. Dr. He Wenxian (Joseph He Wenxian), ele comunicou o interesse em acordos e convênios com instituições brasileiras. Atualmente, a Fujian Business University conta com acordos de cooperação com a Alemanha, Austrália, Canadá e Taiwan e o intercâmbio é uma das características desta instituição. Segundo o reitor, mais de $80 \%$ dos estudantes da universidade realizam algum tipo de intercâmbio em universidades no exterior. Como uma das ações de internacionalização, a universidade recebe anualmente 50 estrangeiros, isentos de pagamento, para cursos que podem variar de 2 semanas a 1 ano.

A universidade conta com excelente infraestrutura, como todas as universidades visitadas. Possui hotel para acomodar docentes e, também, apartamentos para alunos.

Os professores possuem nível muito bom de proficiência em língua inglesa, considerando que sua área de atuação seja a administração ou a contabilidade. Os alunos apresentam um quadro bastante variado, em que os veteranos demonstram uma facilidade maior de comunicação. Mas uma das palestras teve que contar com tradução do inglês para o mandarim de modo a facilitar a compreensão dos estudantes.

A universidade recebe professores da Alemanha e Austrália com assiduidade, que ficam por um semestre ministrando cursos na área de administração ou de língua estrangeira para estudantes.

\section{Conclusão}

Da reflexão sobre o contexto políticoeconômico brasileiro com a China deriva a conclusão de que as parcerias acadêmicas com a pósgraduação em Linguística e Literatura carecem de uma diretriz específica focada no estreitamento intercultural entre os dois países. Por um outro lado, é nítida a abertura, por parte do governo chinês, para a expansão da língua portuguesa em seu território. As universidades chinesas, mesmo jovens e com um quadro docente com pouca titulação, não se inibem em buscar parcerias com universidades de outros países, conforme demonstram os relatos de prospecção. Aliado a isso as análises sobre a expansão do ensino superior na China apresentadas por Gong \& Martinez (2018) reiteram que com a expansão forma-se um sistema de ensino jovem, que busca em convênios acadêmicos a bases para sua consolidação.

A China apresenta-se, portanto, com um enorme potencial para estabelecimento de convênios 
in e out bound, isso é, para recepção de pesquisadores brasileiros em seu território, como para o envio de estudantes e docentes para atuarem em programas de pós-graduação brasileiros. Destaco, por fim, o importante papel a ser desempenhado pela área de Linguística e Literatura nesse processo, ao capacitar pesquisadores estrangeiros com o acesso à língua portuguesa, como também para promover debates sobre interculturalidade, de modo a estreitar as relações sociais e interpessoais entre os cidadãos dos dois países.

\section{Referências}

ANDRÉ, Carlos Ascenso. O Português na China Um Caso de Sucesso. In: Administração. n. 116, vol. XXX, jul-dez., 2017, 197-202. In: https://www.safp.gov.mo/safppt/download/WCM 0 $\underline{65050}$ - Acessado em 11/06/2019.

ARAÚJO, E. H. F. Trump e o Ocidente. In: Cadernos de Política Exterior. Instituto de Pesquisa de Relações Internacionais. Ano III, n. 6. Brasília: FUNAG, 2017, pp. 323-357.

BBC. Sete gráficos para entender a impressionante transformação econômica da China. In: https://www.bbc.com/portuguese/noticias/2015/09/ 150926 china urbanizacao cc - Acessado em 29/05/2019.

BRAZIL. Ministério das Relações Exteriores. República Popular da China. In: http://www.itamaraty.gov.br/pt-BR/ficha-pais/4926republica-popular-da-china - Acessado em 29/05/2019.

BUENO, André. Relações Brasil-China: Novas Perspectivas. In: Anais X Simpósio Electrônico Internacional Sobre Política China. Mar. 2019. In: https://www.academia.edu/38646156/RELA\%C3\% 87\%C3\%95ES BRASILCHINA NOVAS PERSPECTIVAS - Acessado em 29/05/2019.

CAPES - Coordenação de Aperfeiçoamento de Pessoal de Nível Superior. Plano nacional de pósgraduação [PNPG] 2011-2020. Brasília: CAPES, 2018.

CARVALHO, Evandro Menezes de. A segunda década do BRICS: entre a expansão e a retração da agenda reformista. In: Idéias, Campinas, SP, v.9, n.2, AOP, jul./dez. 2018. Disponível em: https://periodicos.sbu.unicamp.br/ojs/index.php/ide ias/article/view/8655187/19321 - Acessado em 29/05/2019.
COSTA, Edivan de Azevedo Silva da. Uma etnografia da comunidade Chinesa na cidade de São Gonçalo, Rio de Janeiro. In: Idéias, Campinas, SP, v.9, n.2, AOP, jul./dez. 2018. Disponível em: https://periodicos.sbu.unicamp.br/ojs/index.php/ide ias/article/view/8655187/19321 - Acessado em 29/05/2019.

DEBORD, G. Sociedade do espetáculo. Rio de Janeiro: Contraponto, 2000.

DIMAS, Antonio. Felina China (Posfácio). In: TELLES, Lygia Fagundes. Passaporte para a China. São Paulo: Cia das Letras, 2011, p. 79-85

G1. PIB do Brasil cresce 1,1\% em 2018 e ainda está no patamar de $2012 . \quad$ In: https://g1.globo.com/economia/noticia/2019/02/28/ pib-do-brasil-cresce-11-em-2018.ghtml Acessado em 28/05/2019.

G1. Economia da China cresce 6,6\% em 2018; taxa é a menor desde $1990 . \quad$ In: https://g1.globo.com/economia/noticia/2019/01/21/ economia-da-china-cresce-66-em-2018.ghtml Acessado em 28/05/2019.

G1. Desigualdade de renda para de cair no Brasil após 15 anos, e número de pobres cresce, aponta ONG. https://g1.globo.com/economia/noticia/2018/11/26/ desigualdade-de-renda-para-de-cair-no-brasilapos-15-anos-e-numero-de-pobres-cresce-apontaong.ghtml - Acessado em 29/05/2019.

GAO, Hongzhi; KNIGHT, John G.; BALLANTYNE, David. Guanxi as a gateway in Chinese-Western business relationships. In: Journal of Business \& Industrial Marketing, Vol. 27, n. 6, 2012. pp. 456 467.

GONG, Cassidy; MARTINEZ, Magdalena. Higher Education Massification in Brazil and China Understanding the Different Approaches in Different Contexts to Strengthen Shared Goals and Interests. Toronto: University of Toronto, 2018.

LOBATO, Lenaura de Vasconcelos Costa. The social issue in the BRICS Project. In: Ciência \& saúde coletiva, vol.23 no.7 Rio de Jan-Jul 2018.

MARÉS, Chico. Principal alvo de Weintraub, ciências sociais e humanas recebem um quarto das bolsas de pesquisas do país. In: Lupa. 17, maio, 2019. https://piaui.folha.uol.com.br/lupa/2019/05/17/dado s-universidades-pesquisa/ - Acessado em 11/06/2019.

NATURE. Brazilian scientists strive to turn politicians into allies. News. 23/05/2019. In: https://www.nature.com/articles/d41586-01901648-y - Acessado em 11/06/2019.

OMONDI, Sharon. The Most Spoken Languages in the World. In: Graphic Maps. 
https://www.graphicmaps.com/the-world-s-mostspoken-languages, Acessado em 28/05/2019.

QS World University Rankings. In: https://www.topuniversities.com/universityrankings/world-university-rankings/2019. Acessado em 29/05/2019.
SILVA, Carlos Freire. Conexões Brasil-China: a migração chinesa no centro de São Paulo. In: Cadernos Metrópole, São Paulo, v. 20, n. 41, pp. 223-243, jan/abr 2018. Disponível em: http://www.scielo.br/scielo.php?script=sci abstract \&pid=S223699962018000100223\&lng=en\&nrm=iso\&t|ng=pt Acessado em 29/05/2019.

\section{COMO CITAR ESSE ARTIGO}

FERNANDES, Frederico Augusto Garcia. CHINA, UMA BREVE PROSPECÇÃO: CONSIDERAÇÕES SOBRE A POLÍTICA DE INTERNACIONALIZAÇÃO BRASILEIRA E A PÓS-GRADỦAÇÃO EM LETRAS. Signo, Santa Cruz do Sul, v. 44, n. 81, dez. 2019. ISSN 1982-2014. Disponível em: $<$ https://online.unisc.br/seer/index.php/signo/article/view/13660>. Acesso em: doi: https://doi.org/10.17058/signo.v44i81.13660. 